\title{
AVALIAÇÃO DA QUALIDADE DO SERVIÇO PRESTADO POR UMA UNIDADE DE ENSINO DA REDE PÚBLICA NA REGIÃO METROPOLITANA DO RECIFE
}

Claudemice C. do N. Matias (UNIVERSIDADE FEDERAL DE PERNAMBUCO) Claude.mice@ hotmail.com Taciana de Barros Jerônimo (UNIVERSIDADE FEDERAL DE PERNAMBUCO) Taciana.barros@gmail.com Fagner José Coutinho de Melo (UNIVERSIDADE DE PERNAMBUCO) Fagner.melo@upe.br

\section{Resumo}

A educação pública para todos e com qualidade é um objetivo governamental e previsto na constituição civil, todavia, faz-se necessário compreender o que se pode chamar, neste contexto, de qualidade. Desta maneira, esta pesquisa possui como objetivo avaliar a qualidade do serviço prestado, considerando a expectativa e percepção dos estudantes e o clima organizacional dos prestadores de serviço, em uma unidade de ensino da rede pública na região metropolitana do Recife. Para avaliar a qualidade foi usado o modelo SERVQUAL, o qual mensura as percepções e expectativas que os clientes possuem a respeito do serviço. E, para diagnosticar o clima organizacional foi aplicado um questionário, elaborado através do referencial teórico. Participaram da pesquisa 7 servidores administrativos, 16 professores e 6 coordenadores, com total de 29 servidores públicos da unidade escola e 60 estudantes, a amostra de estudantes participantes da pesquisa foi estimada por conveniência, sendo uma amostra não probabilística. Desta maneira, os resultados deste trabalho refletem a amostra estudada e não devem ser generalizados. Foi encontrado que há grau elevado de satisfação nos aspectos de relacionamento com a gestão e coordenação, e insatisfação quanto à comunicação organizacional. Já os aspectos da avaliação da qualidade que contribuem para a qualidade do serviço são: boa localização e ser de fácil acesso; ter ambiente físico limpo, bem iluminado e com temperatura agradável; ter professores e servidores sempre tem dispostos em ajudar.

Palavras-Chaves: Avaliação da qualidade, avaliação de clima, Escola técnica, SERVQUAL.

\section{Introdução}

A educação é o setor chave para o desenvolvimento de uma nação, a crise na educação revela a crise nos demais setores, como o setor produtivo que diretamente será afetado pela qualificação da mão de obra. Apesar da escola não gerar a desigualdade, pois ela já se desenvolve antes da escola, a educação é de fato o que vai direcionar quem vai e quem não vai ser incluído na sociedade. A qualidade do serviço escolar é o que pode ou não promover o desenvolvimento social mais justo e igualitário. E vale ressaltar que a educação possui diversas interpretações e que não se trata apenas da educação com viés econômico, mas na educação como um direito humano, o que nos faz compreender que a educação de qualidade apoia todos os direitos humanos (MOROSINI, 2009; JERONIMO et al., 2016). Estudos revelam a urgente necessidade de uma educação para a vida, com qualidade sociocultural (PADILHA; SILVA, 2004) e socioambiental (PADILHA, 2007). 
"Se queremos uma educação para a vida, para a satisfação individual e coletiva, que nos ajude a ter um contato sensível e consciente com o belo e, ao mesmo tempo, que nos ensine a cuidar do planeta em que vivemos de forma sustentável, temos, então de falar não simplesmente de qualidade de educação, mas, como prefiro chamar, de qualidade sociocultural e socioambiental da educação. Trata-se, nesse caso, de trabalharmos na perspectiva eco-político-pedagógica, que nos remete à formação ampla e integral das pessoas, visando à recuperação da totalidade do conhecimento, dos saberes, dos sentimentos, da espiritualidade, da cultura dos povos e da história da humanidade em íntima conexão com todas as formas de vida no nosso ecossistema" (PADILHA, 2007, p. 22).

Considerando o exposto, esta pesquisa possui como objetivo avaliar a qualidade do serviço prestado por uma unidade de ensino da rede pública na região metropolitana do Recife. Assim, será realizado um diagnóstico da qualidade nos serviços cujo esforço concretiza-se a partir uma análise do clima organizacional para mensurar aspectos relevantes, como a motivação interna, que implicam na qualidade do serviço educacional e a análise da qualidade do serviço considerando a expectativa e percepção dos usuários, neste caso os estudantes.

Desta maneira, esta pesquisa foi estruturada em cinco seções. Na primeira seção foi apresentada a introdução. Na segunda foi descrita a fundamentação teórica, na terceira foi descrita a metodologia da pesquisa, na quarta os resultados e por fim as conclusões da pesquisa.

\section{Fundamentação teórica}

Com o intuito de atingir o objetivo desta pesquisa, nesta seção será apresentado os principais conceitos que irão nortear esta pesquisa, como: avaliação da qualidade em serviços e clima organizacional.

\subsection{Avaliação da qualidade em Serviços}

Vários autores se debruçam sobre o conceito de serviços, entre estes, Kotler (1998); Gianessi e Corrêa (1994); Lovelock e Wright (2001), Palmer e Cole (1995), Ferraz et al., (2018) e Carvalho et al., (2018) os quais, expõe características relacionadas aos serviços como intangibilidade, inseparabilidade, variabilidade e perecibilidade. Segundo Kotler (1998) essas características podem ser apresentadas como: 
- Intangibilidade dos serviços: não podem ser vistos, provados, sentidos, antes da compra.

- Inseparabilidade dos serviços: a produção e o uso são simultâneos.

- Variabilidade dos serviços: a qualidade depende de quem os fornece, bem como de quando, onde e como são fornecidos.

- Perecibilidade dos serviços: não podem ser armazenados para venda ou uso posterior.

Pode-se reiterar que Parasuraman et al. (1988), também apresentam três características dos serviços:

- Simultaneidade: serviços são consumidos quase que simultaneamente ao momento em que são produzidos;

- Intangibilidade: os serviços representam um produto que não é físico.

- Heterogeneidade: A variedade relacionada a qualidade depende do fator humano.

Para medir a qualidade do serviço, Parasuraman, Zeithaml e Berry (1988) propuseram um modelo, através das diferenças entre percepções e expectativas que os clientes possuem a respeito do serviço. Este modelo é o SERVQUAL, no qual a qualidade percebida pelos usuários dos serviços é medida em função da diferença entre a expectativa e sua percepção sobre o desempenho do serviço (NETO et al., 2018). O SERVQUAL é composto por cinco dimensões, as quais são:

- Tangibilidade: corresponde as instalações físicas, materiais e colaboradores disponíveis.

- Confiabilidade: relacionado comprometimento de realizar o serviço conforme prometido.

- Presteza: capacidade de atender ao usuário de forma positiva perante eventuais dificuldades.

- Segurança: capacidade de passar confiança e suprir suas necessidades.

- Empatia: tratar o usuário da melhor forma, sendo cuidadoso, oferecendo atenção personalizada.

Considerando estas dimensões o SERVQUAL possui 22 itens, os quais são aplicados em duas etapas, a primeira analisa a expectativa do usuário dos serviços, e a segunda à percepção que 
o mesmo possui a respeito do serviço após experimentado. A diferença entre a expectativa e percepção é o que proporá a análise do SERVQUAL demonstrando os gaps, ou lacunas entre a expectativa e realidade na percepção dos usuários do serviço. Quanto maior for o valor do gap, maior é a qualidade do serviço (NETO et al., 2018; OLIVEIRA et al., 2019).

\subsection{Clima organizacional}

$\mathrm{Na}$ era da globalização os desafios das organizações giram em torno da diversidade e complexidade do ambiente em que operam. A dinâmica do ambiente promove um status de turbulências e descontinuidades que tornam o presente obsoleto mediante a velocidade da inovação tecnológica, a qual exige da organização uma rápida adaptação às mudanças, com flexibilidade de manter-se competitiva no mercado (JERÔNIMO et al., 2016).

As organizações são operadas por pessoas e estas são essenciais para o alcance os objetivos estratégicos. A pesquisa de clima organizacional busca mesurar os sentimentos das pessoas que atuam na organizacional e o quanto estes sentimentos estão relacionados com o grau de satisfação e motivação dos funcionários. Teixeira et al. (2005) definem clima organizacional como percepções, opiniões e sentimentos que são expressados pelo meio de comportamentos por um grupo ou organização, em um dado momento.

Sendo uma ferramenta estratégica para o diagnóstico do grau de satisfação da organização, a elaboração da pesquisa de clima organizacional deve estar alinhada com o planejamento estratégico da organização devendo ser aplicado no questionário variáveis que sejam fundamentais para o sucesso da análise do clima organizacional, ou seja, ao realizar a pesquisa a organização deve estar atento ao feedback para todos quanto aos resultados e melhorias de curto prazo e longo prazo. A ausência de feedback, bem como a ausência de melhorias, nos aspectos apontados pela pesquisa, pode gerar mais insatisfação e até mesmo a perca da credibilidade quanto à própria pesquisa (AQUINO et al., 2019).

\section{Metodologia}

Esta pesquisa foi realizada em uma unidade de serviço em educação da rede pública localizada na região metropolitana do Recife. A escola estudada é uma unidade de educação de base integral médio-técnico, com mais de 100 anos de atuação. Para a pesquisa de clima organizacional foi realizada utilizando um questionário Google Forms, envolvendo os setores administrativos, os professores da base técnica integral, e coordenadores técnicos e pedagógicos. 
O Quadro 1 apresenta um compêndio das questões do questionário. O questionário foi elaborado a partir da escolha de alguns critérios que não seguiu estritamente um modelo específico, mas a partir dos modelos científicos existentes como de Litwin e Stringer (1968), Kolb (1986) e Sbragia (1983). Assim, foram formuladas questões que englobassem critérios como Conformismo, Clareza Organizacional, Comunicação, Liderança, Conflito e Cooperação. Antes da aplicação, foi realizada uma reunião com os participantes e equipe da gestão, para compreensão e orientação a respeito da pesquisa

Quadro 1 - Questões do para avaliação do clima organizacional

\begin{tabular}{|c|c|}
\hline \multicolumn{2}{|r|}{ PERGUNTAS } \\
\hline \multicolumn{2}{|r|}{ COMUNICAÇÁO INTERNA } \\
\hline 1 & QUAL SEU SENTIMEINTO QUANTO A COMUNICAÇÄAO INTERNA NA ESCOLA? \\
\hline 2 & $\begin{array}{l}\text { AS INFORMAÇÖES SÄ́O CLARAS QUANTO AS METAS E OBJETTVOS ANUAIS E } \\
\text { BIMIESTRAIS? }\end{array}$ \\
\hline 3 & $\begin{array}{l}\text { QUAL SEU SENTIMIENTO QUANTO AO TEMPO DE REUNIÓES PARA INFORMAÇÖES E } \\
\text { COMUNICACCŌES? }\end{array}$ \\
\hline 4 & QUAL SEU NIVEL DE SATISFAÇÄO COM INFORMAÇÖES NO CANAL WHATSAP? \\
\hline 5 & $\begin{array}{l}\text { QUAL SEU NIVEL DE SATISFAÇÁO COM INFORMAÇÖES NO C.ANAL WHATSAP NO POS } \\
\text { HORARIO? }\end{array}$ \\
\hline 6 & A MISSÄA, VISÄA E VALORES DA ORGANIZAÇÄ̈O SÄO DISCUTUDOS EM REUNIŌES? \\
\hline 7 & $\begin{array}{l}\text { O PLANO POLITICO PEDAGOGICO E DISPONIVEL PARA CONSULTA, DISCUSSÄO, } \\
\text { MODIFICAÇÄAO E ATUALIZAÇÄ̈O PELA COMUINDADE ESCOLAR? }\end{array}$ \\
\hline \multicolumn{2}{|c|}{ SUGESTÓES: } \\
\hline \multicolumn{2}{|r|}{ RELACIONAMENTO INTERPESSOAL } \\
\hline 8 & QUAL SEU NIVEL DE SATISFAÇÁA COM O CLIMA DAS RELAÇÖES ENTRE COLEGAS? \\
\hline 9 & $\begin{array}{l}\text { QUAL SEU NIVEL DE SATISFAÇÁAO QUANTO AOS PRAZOS E DATAS PRE ESTABELECIDOS } \\
\text { PARA PROJETOS OU TAREFAS? }\end{array}$ \\
\hline 10 & $\begin{array}{l}\text { QUAL SEU SENTIMENTO QUANTO A COOPERAÇÄO ENTRE OS COLEGAS DO TIME DA } \\
\text { COORDENACÄO? }\end{array}$ \\
\hline 11 & $\begin{array}{l}\text { QUAL SEU NIVEL DE S.ATISFAÇȦO QUANTO AS RELAÇÖES PROFISSIONAIS COM OS } \\
\text { PROFESSORES? }\end{array}$ \\
\hline 12 & $\begin{array}{l}\text { QUAL SEU NIVEL DE SATISFAÇÁO COM O CLIMLA DAS RELAÇÖES PROFISSIONAIS COM A } \\
\text { GESTAOO? }\end{array}$ \\
\hline 13 & A GESTÄO EXERCE UMAA LIDERANÇA DEMOCRATICA? \\
\hline 14 & SUAS SUGESTÖES SÄO ACEITAS E DISCUTIDAS DEMOCRATICAMENTE? \\
\hline 15 & $\begin{array}{l}\text { QUAL SEU SENTIMENTO QUANTO AO NTVEL DE TRANSPARENCIA NAS TOMADAS DE } \\
\text { DECISÖES? }\end{array}$ \\
\hline 16 & SENTE-SE MOTIVADO E APOIADO PELA GESTÄO NOS PROJETOS PEDAGOGICOS? \\
\hline 17 & EXISTE FEEDBACK DA GESTÄO QUANTO AO DESEMIPENHO? \\
\hline 18 & SEMTIE-SE ACEITO E MOTIVADO A TRABALHAR EM EQUIPE? \\
\hline & 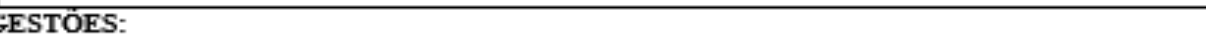 \\
\hline
\end{tabular}

Fonte: Esta pesquisa, 2020.

Participaram da pesquisa 7 servidores administrativos, 16 professores e 6 coordenadores, com total de 29 servidores públicos da unidade escola.

Para a avaliação da qualidade do serviço prestado foi utilizado o modelo SERVQUAL adaptado aplicado junto aos estudantes com uma amostra composta por 60 estudantes. A pesquisa foi realizada através de um questionário SERVQUAL, aplicado na escola, com um total de sessenta estudantes participantes, divididos entre 20 estudantes da $1^{\text {a }}$ série, 20 
estudantes da $2^{\text {a }}$ série e 20 estudantes da $3^{\text {a }}$ série do ensino Médio, realizada no mês de novembro do ano 2019. A amostra de estudantes participantes da pesquisa foi estimada por conveniência, sendo uma amostra não probabilística. Desta maneira, os resultados deste trabalho refletem a amostra estudada e não devem ser generalizados. O questionário foi aplicado considerando os 22 itens do modelo SERVQUAL, realizado em duas etapas. $\mathrm{Na}$ primeira o objetivo foi identificar as expectativas e na segunda, identificar a percepção para as mesmas. Desta maneira, esta pesquisa pode classificada como um estudo de caso. Quanto aos dados, essa pesquisa pode ser classificada como qualitativa/quantitativa.

\section{Resultados}

\subsection{Pesquisa de clima organizacional}

O setor administrativo apresentou um grau elevado de satisfação nos aspectos de relacionamento com a gestão e coordenação, compactuando com a afirmação de satisfação no exercício de uma gestão democrática. Neste mesmo setor, foram verificados alguns pontos de alerta de insatisfação, os quais envolvem critérios relacionados à comunicação e cooperação entre os colegas. O gráfico 1 a seguir, apresenta um compêndio dos resultados encontrados com a aplicação do questionário no setor administrativo.

Gráfico 1: Pesquisa de Clima Organizacional Administrativos

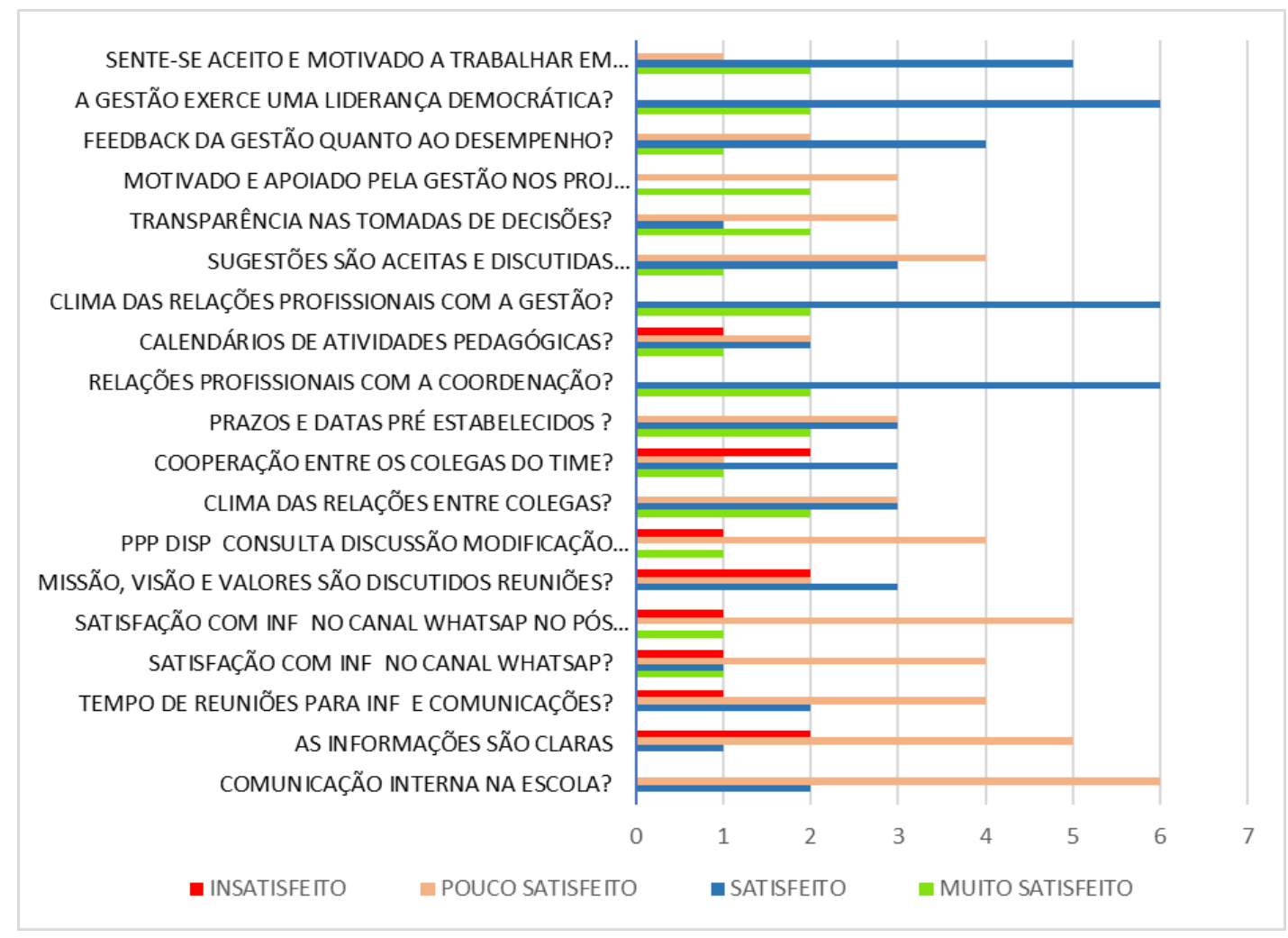

Fonte: Esta pesquisa, 2020. 
A comunicação é um fator crucial na organização e quando não é clara e objetiva, pode desencadear conflitos como o verificado como insatisfação na cooperação entre os colegas. Para uma análise geral, os dados foram tabulados, somando pouco satisfeito e insatisfeito como insatisfação, e satisfeito e muito satisfeito como satisfação, conforme exposto no Gráfico 2.

Gráfico 2: Pesquisa de Clima Organizacional - Administrativos

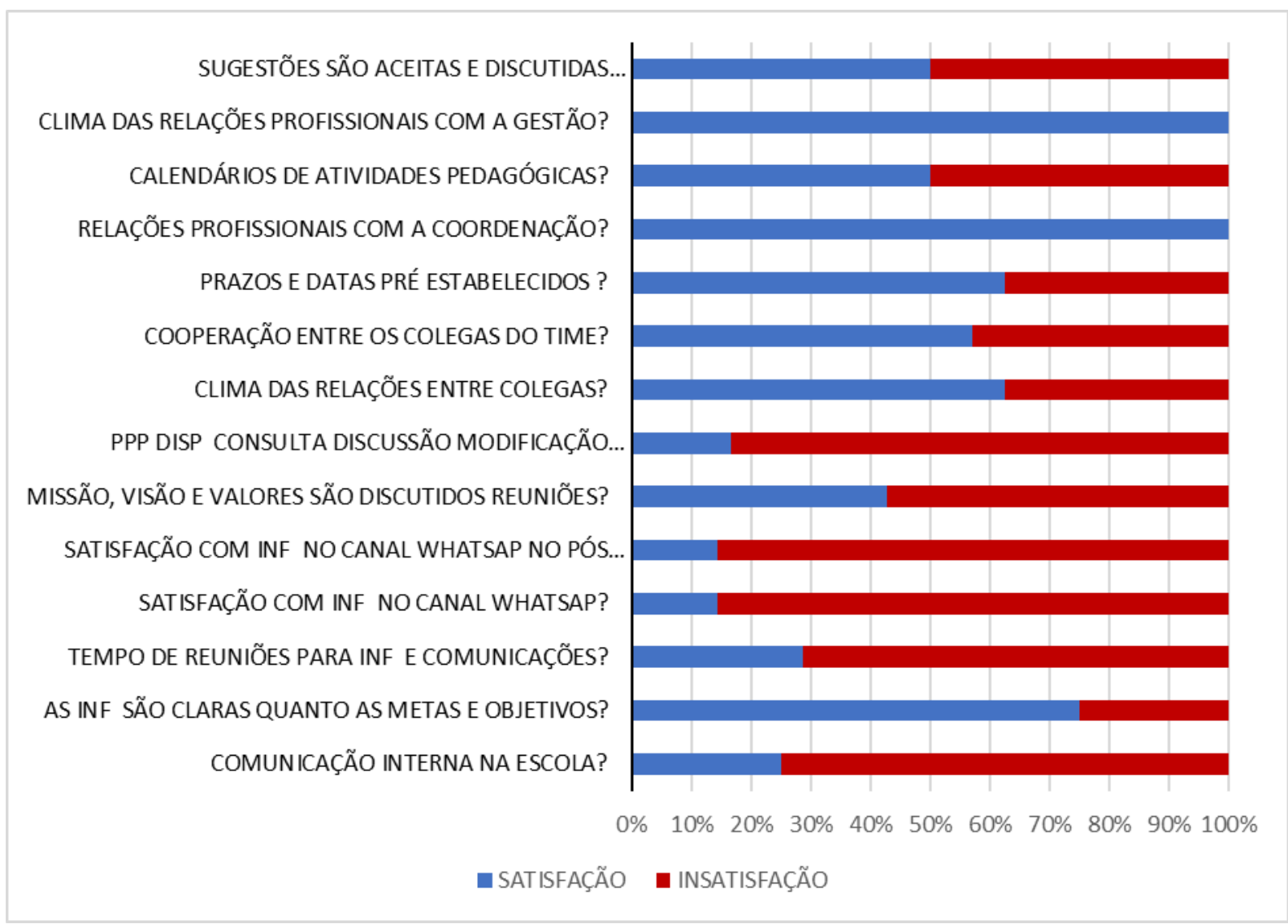

Fonte: Esta pesquisa, 2020.

Desta forma alguns aspectos receberam destaques, como WhatsApp pós horários e Comunicação WhatsApp gerando cerca de $87 \%$ de insatisfação respectivamente, Projeto político pedagógico gerando cerca de $83 \%$ insatisfações, Comunicação interna com $72 \%$ insatisfação e Tempo de reuniões com 43\% insatisfação.

Sendo assim foram identificados aspectos relevantes, para serem elaboradas ações corretivas para mitigar os elevados graus de insatisfação. O gráfico 3 a seguir, apresenta um compêndio dos resultados encontrados com a aplicação do questionário com os professores. Os professores apresentaram satisfação quanto às informações das metas e objetivos organizacionais, a cooperação entre a equipe e o relacionamento com a gestão e coordenação. 
Por outro lado, o grupo revelou um acentuado grau de insatisfação na disponibilidade do Projeto Político Pedagógico (PPP), seja para consulta ou reformulação do mesmo.

Gráfico 3: Pesquisa de Clima Organizacional - Professores

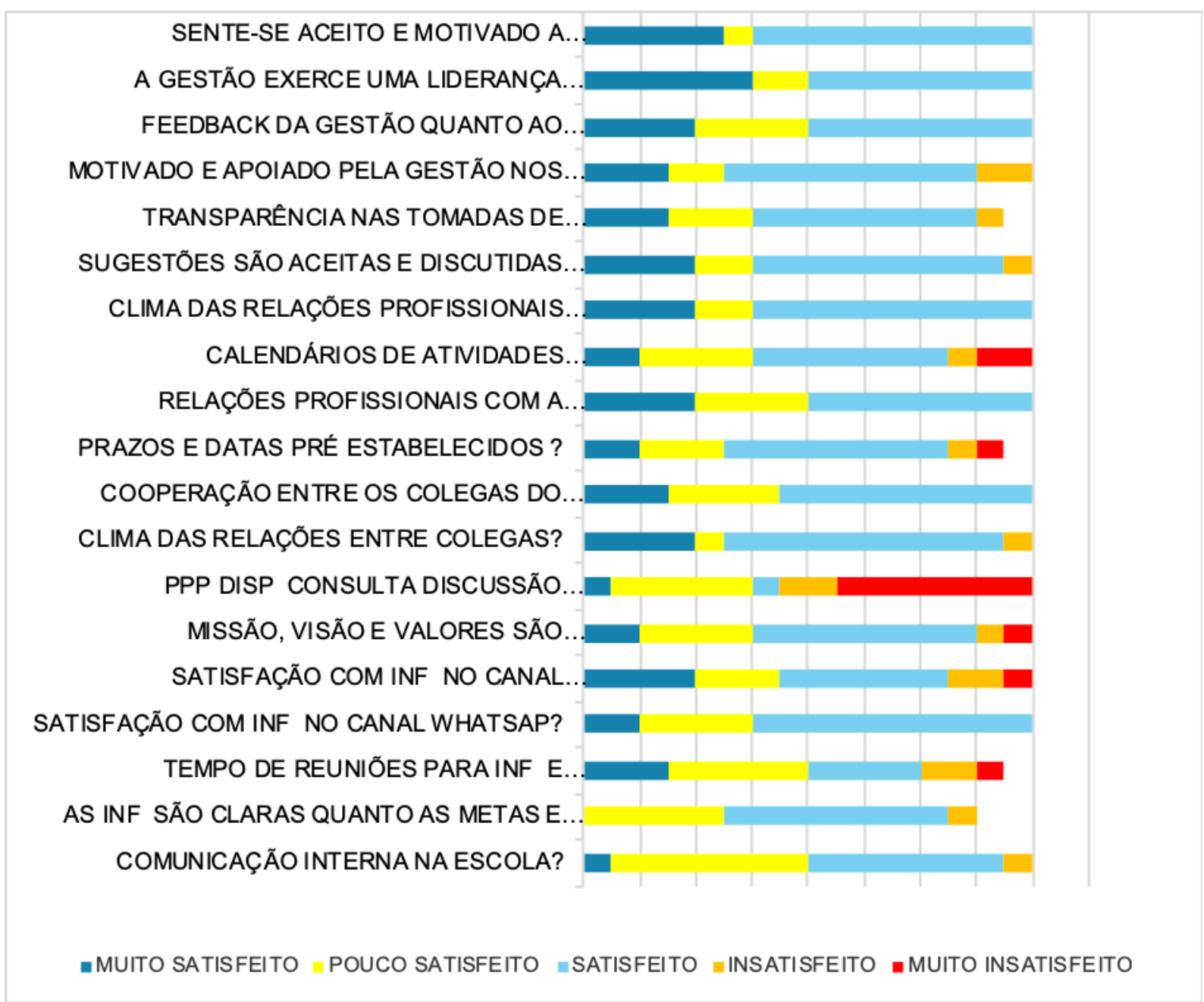

Fonte: Esta pesquisa, 2020.

Quando os dados foram tabulados somando pouco satisfeito, insatisfeito e muito insatisfeito como insatisfação, e satisfeito, muito satisfeito como satisfação conforme Gráfico 4 demonstra, outros aspectos ganharam destaque, além do PPP, 87\% de insatisfação, a comunicação interna com $53 \%$ de insatisfação, o tempo das reuniões para informações $47 \%$ de insatisfação, calendários pedagógicos com 43\%. Recebem destaque com alto grau de satisfação o trabalho em equipe e a liderança democrática exercida pela gestão escolar que ultrapassa $90 \%$ de satisfação para o primeiro e se aproxima deste percentual o segundo. 
Gráfico 4: Clima Organizacional Geral - Professor

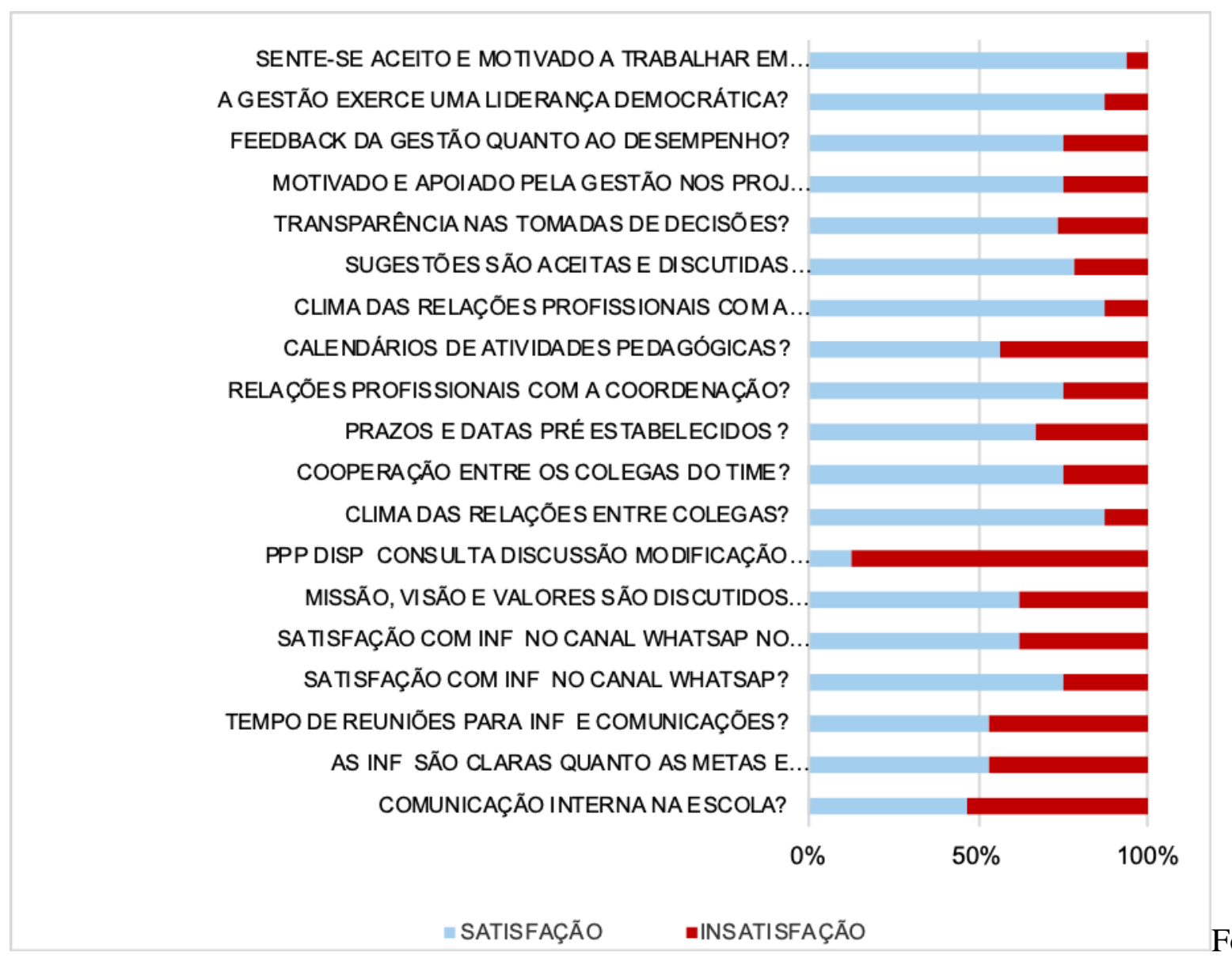

nte: Esta pesquisa, 2020.

O gráfico 5 a seguir, apresenta um compêndio dos resultados encontrados com a aplicação do questionário com a coordenação. Os resultados da pesquisa, demonstram que para a coordenação, os aspectos com elevada satisfação se enquadram na prática de uma liderança democrática e participativa. Alguns coordenadores revelaram um nível elevado de insatisfação relacionado a cooperação entre o time de coordenadores, a indisponibilidade do PPP, e as informações no canal WhatsApp no pós horário (Gráfico 5). 
Gráfico 5: Pesquisa de Clima Organizacional - Coordenação

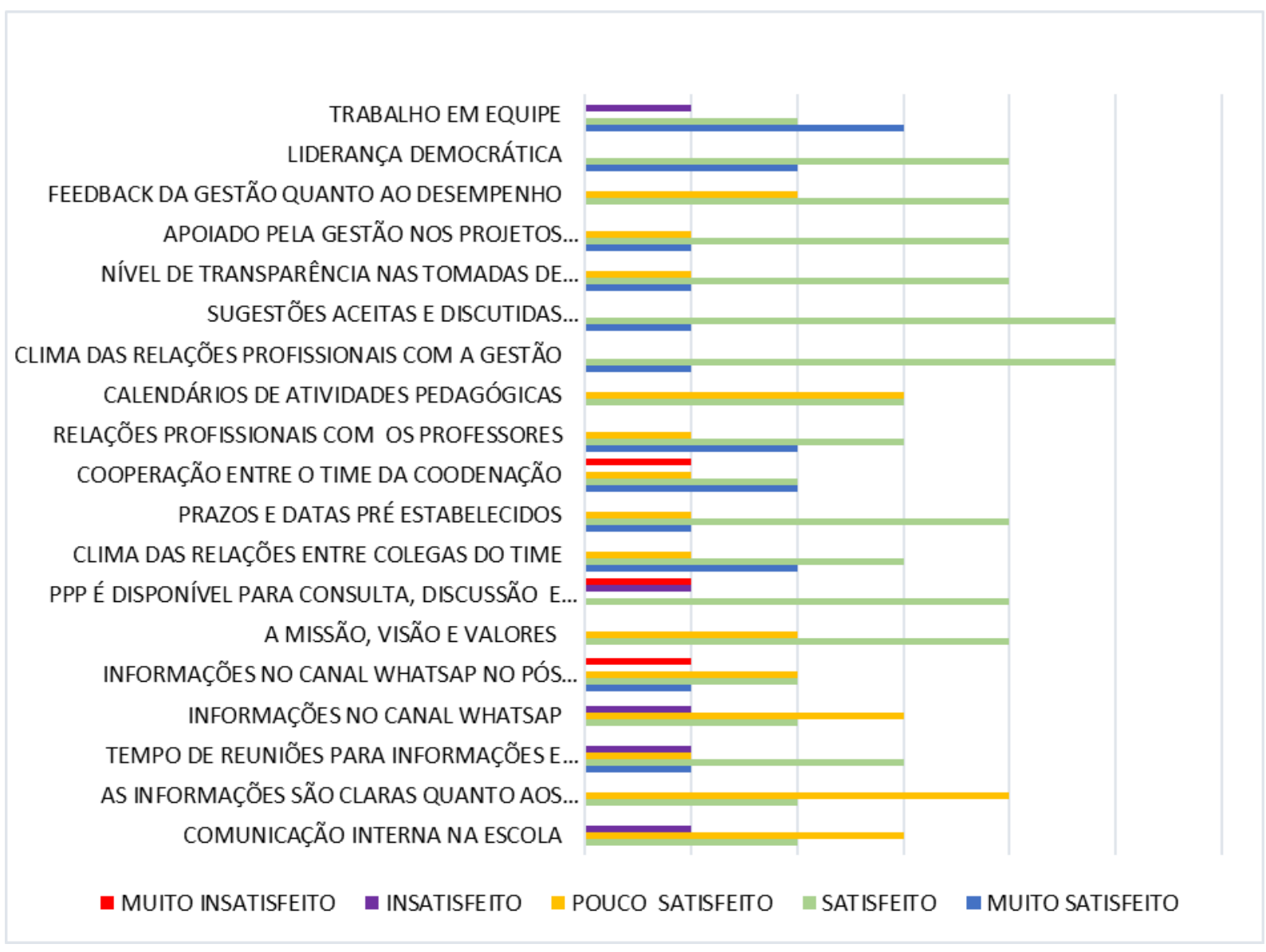

Fonte: Esta pesquisa, 2020.

Quando os dados foram tabulados, somando pouco satisfeito, insatisfeito e muito insatisfeito como insatisfação, e satisfeito mais muito satisfeito como satisfação conforme Gráfico 6 demonstra, a insatisfação com o aspecto comunicação, ultrapassa os $65 \%$ dos participantes, seja relacionada a comunicação interna, aos objetivos e no próprio Whatssap. Por outro lado, $100 \%$ dos respondentes possuem satisfação com a gestão democrática e participativa.

Merecem destaques nesta análise a satisfação da equipe com o modelo de liderança democrática e participativa, adotado pela gestão. Bem como, vale acentuar que é necessário desenvolver planos de ação para corrigir as falhas de comunicação e atualização do PPP, visto que são aspectos que apresentam em todos os setores insatisfação. 
Gráfico 6: Clima Organizacional Geral - Coordenação

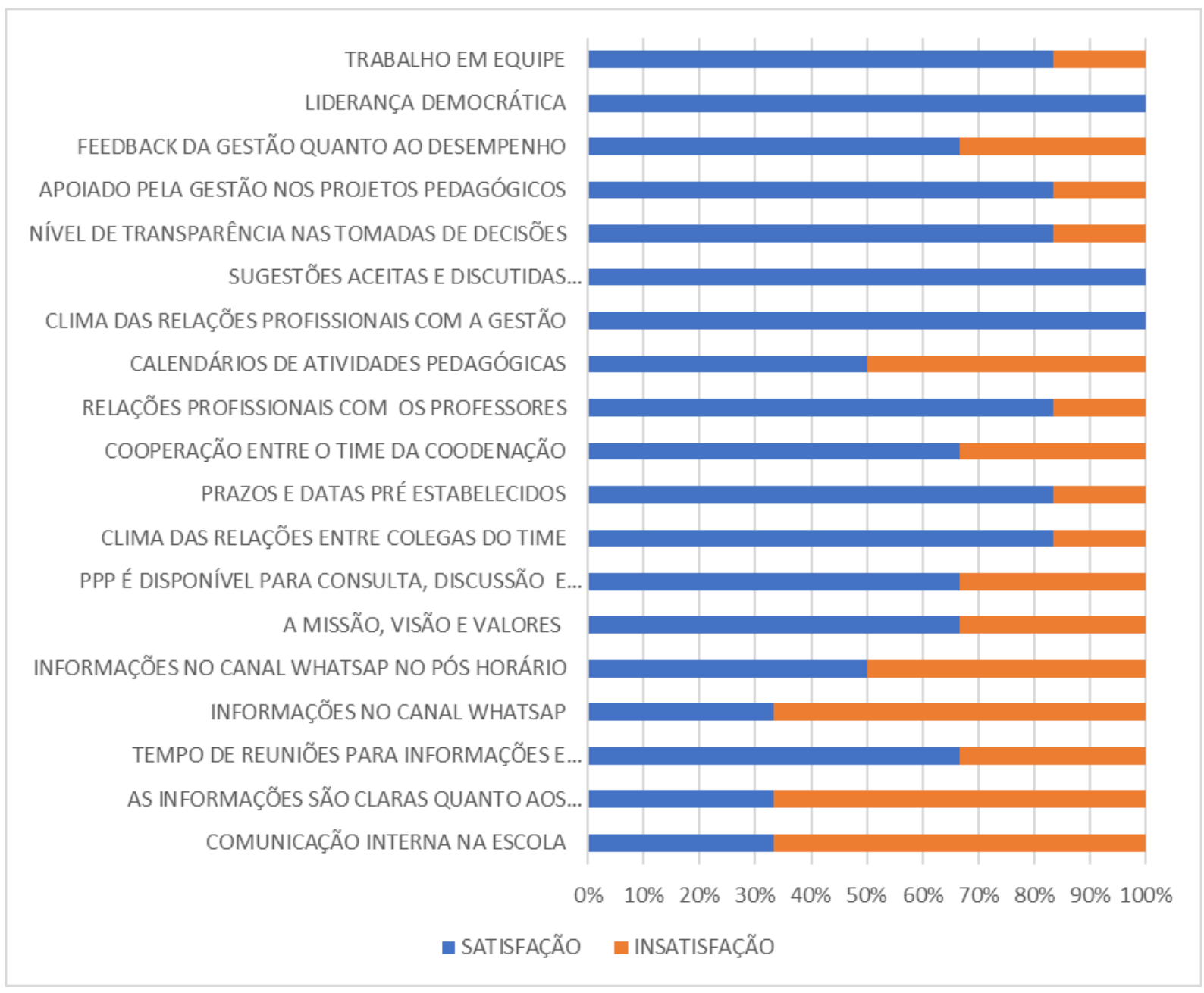

Fonte: Esta pesquisa, 2020.

\subsection{Mensuração da qualidade dos serviços a partir do modelo SERVQUAL}

Os estudantes desta amostra estão matriculados na base integral dos cursos técnicos de Mecatrônica, Mecânica, Manutenção e Suporte em Informática e Logística. Os gêneros dos entrevistados correspondem a $58 \%$ do sexo masculino e $42 \%$ do sexo feminino.

A maioria dos estudantes teve a formação do ensino fundamental exclusivamente em escola da rede pública, o que corresponde a $42 \%$ do total, $28 \%$ são estudantes que tiveram o ensino fundamental exclusivo na rede privada de ensino e $30 \%$ tiveram sua formação parte em rede privada, parte em rede pública no ensino fundamental.

A partir da aplicação do questionário, os dados foram tabulados e as médias entre expectativa e percepção identificadas para cada item. O resultado da diferença entre percepção e expectativas médias revelam os gaps, ou seja, as lacunas. Quando os valores dos gaps são positivos, demonstra uma qualidade satisfatória. Quando os gaps são negativos, demostram 
qualidade insatisfatória. Quanto maior o valor positivo, maior satisfação, caso contrário, maior insatisfação relacionada a qualidade.

A Tabela 1 apresenta as médias das expectativas, percepções e dos gaps para cada dimensão do SERVQUAL. Na dimensão da tangibilidade, o item 2, corresponde ao ambiente físico limpo, bem iluminado e com temperatura agradável, a expectativa foi o de maior valor para este grupo, assim como o item 3, revelou maior percepção dos estudantes, considerando boa localização e é de fácil acesso. A prioridade crítica, nesta dimensão, como revela o quartil dos gaps na Tabela 1, é o item 4 relacionado às instalações físicas das salas de aula.

Tabela 1 - Médias do SERVQUAL

\begin{tabular}{|c|c|c|c|c|c|c|}
\hline \multirow[t]{2}{*}{ DIMENSÕES } & \multicolumn{2}{|c|}{ EXPECTATIVAS } & \multicolumn{2}{|c|}{ PERCEPÇÕES } & \multicolumn{2}{|c|}{ GAPS } \\
\hline & ÍTEM & MÉDIA & ÍTEM & MÉDIA & ÍTEM & MÉDIA \\
\hline \multirow{4}{*}{ 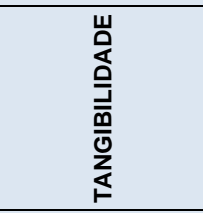 } & 1 & 4,68 & 1 & 2,47 & 1 & $-2,22$ \\
\hline & 2 & 4,78 & 2 & 2,37 & 2 & $-2,42$ \\
\hline & 3 & 4,27 & 3 & 3,62 & 3 & $-0,65$ \\
\hline & 4 & 4,70 & 4 & 2,23 & 4 & $-2,47$ \\
\hline \multirow{5}{*}{ 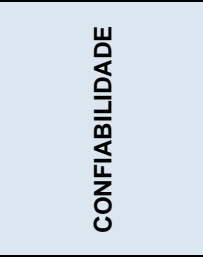 } & 5 & 4,70 & 5 & 2,68 & 5 & $-2,02$ \\
\hline & 6 & 4,63 & 6 & 2,98 & 6 & $-1,65$ \\
\hline & 7 & 5,55 & 7 & 3,32 & 7 & $-2,23$ \\
\hline & 8 & 4,40 & 8 & 3,05 & 8 & $-1,35$ \\
\hline & 9 & 3,47 & 9 & 2,78 & 9 & $-0,68$ \\
\hline \multirow{4}{*}{ 离 } & 10 & 4,22 & 10 & 3,07 & 10 & $-1,15$ \\
\hline & 11 & 4,17 & 11 & 3,22 & 11 & $-0,95$ \\
\hline & 12 & 3,38 & 12 & 2,82 & 12 & $-0,57$ \\
\hline & 13 & 3,85 & 13 & 2,65 & 13 & $-1,20$ \\
\hline \multirow{4}{*}{ 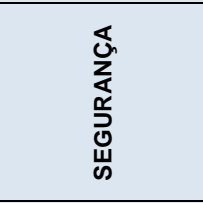 } & 14 & 4,47 & 14 & 2,25 & 14 & $-2,22$ \\
\hline & 15 & 4,53 & 15 & 3,42 & 15 & $-1,12$ \\
\hline & 16 & 4,68 & 16 & 3,63 & 16 & $-1,05$ \\
\hline & 17 & 4,40 & 17 & 3,28 & 17 & $-1,12$ \\
\hline \multirow{5}{*}{ 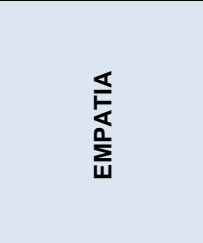 } & 18 & 3,77 & 18 & 2,87 & 18 & $-0,90$ \\
\hline & 19 & 3,53 & 19 & 2,72 & 19 & $-0,82$ \\
\hline & 20 & 4,47 & 20 & 2,58 & 20 & $-1,88$ \\
\hline & 21 & 3,90 & 21 & 2,57 & 21 & $-1,33$ \\
\hline & 22 & 4,12 & 22 & 2,58 & 22 & $-1,53$ \\
\hline
\end{tabular}

Fonte: Esta pesquisa, 2020.

Na dimensão da confiabilidade o item 5 relacionado às informações, a coordenação/diretoria transmite todas as informações necessárias de forma confiável e precisa (instruções claras e confiáveis) a expectativa foi o de maior valor, enquanto na percepção, o item 7 revela que servidores e professores passam confiança/credibilidade aos seus alunos. Todavia os gaps foram negativos com destaque para o item 5 com maior insatisfação. 
A presteza, capacidade de atender ao usuário de forma positiva perante eventuais dificuldades, também apresentou gaps negativos. O item 10 foi o que apresentou destaque na expectativa dos estudantes, esperar que os professores e servidores, sempre tem boa vontade em te ajudar. Esta dimensão, não possui itens enquadrados como prioridade crítica, mas como prioridade média.

A dimensão da segurança, capacidade de passar confiança e suprir suas necessidades, as expectativas mais elevadas estão no item 16, espera-se que os servidores e professores sejam educados. A prioridade crítica está sobre o aspecto da segurança no item 14, o que revela insegurança de confiar na segurança oferecida pela escola.

A Tabela 2 mostra quais prioridades devem ser levadas em consideração para elaboração de planejamentos e tomadas de decisões que desenvolvam um índice de qualidade satisfatório para os usuários deste serviço.

Tabela 2. Grau de criticidade das expectativas, percepções e gaps

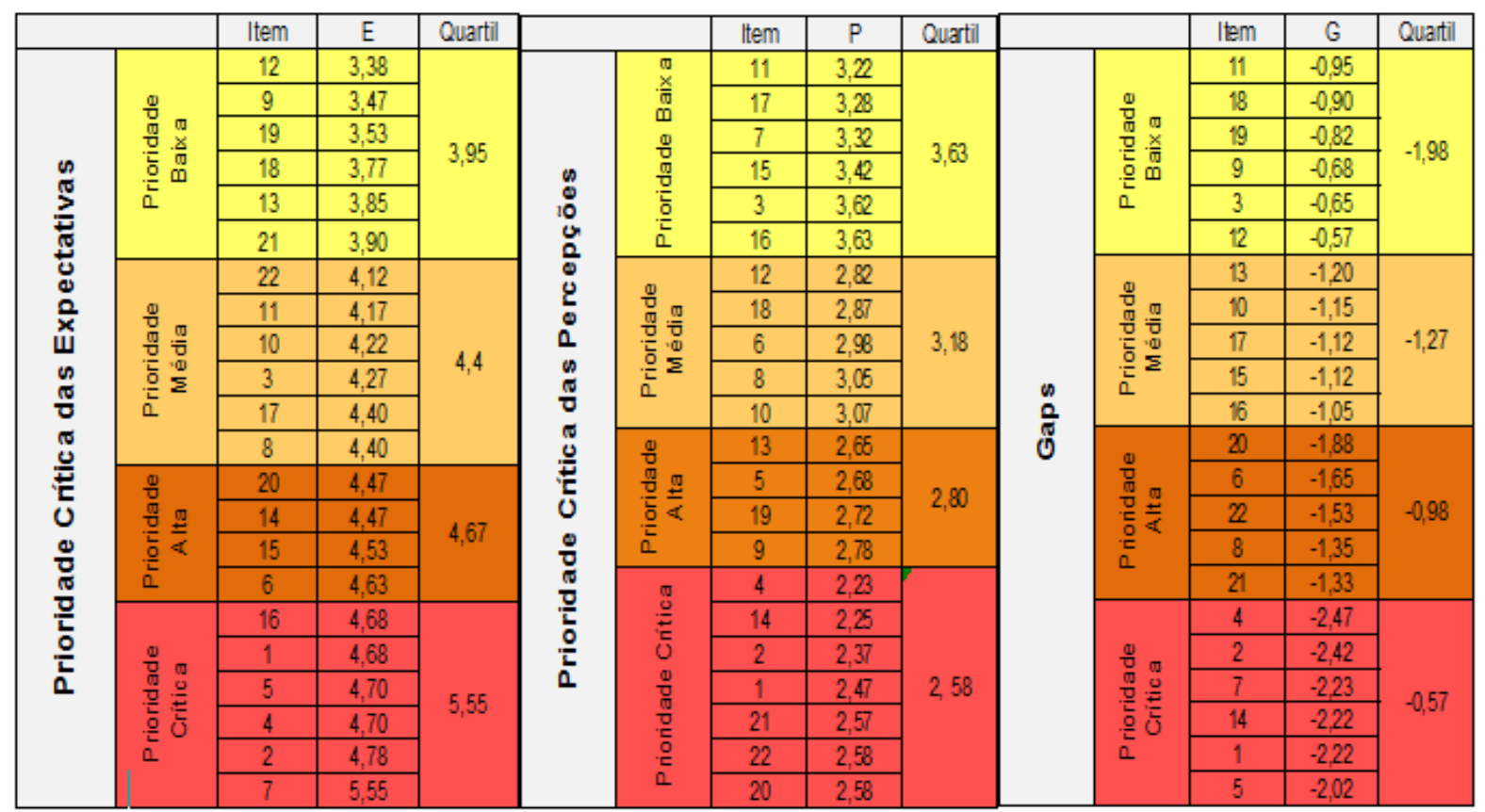

Fonte: Esta pesquisa, 2020.

As maiores expectativas estão enquadradas na dimensão da tangibilidade, itens 1,2 e 4, seguida de confiabilidade, itens 5 e 7 e na dimensão de segurança apenas o item 16. Estes itens possuem classificação no quartil de prioridade crítica que devem ser considerados como os atrativos maiores na escolha dos estudantes.

Quanto às percepções, as prioridades críticas estão mais presentes nas dimensões tangibilidade e empatia, os itens 1, 2, 4, 20,21 e 22 e apenas o item 14 da dimensão da segurança. Os gaps da Tabela 2, são os resultados da qualidade do serviço escolar. Quando os 
números são positivos, há qualidade satisfatória, porém quando apresentam números negativos, os gaps revelam qualidade insatisfatória. Pelo exposto na Tabela 2, todas as dimensões apresentam qualidade insatisfatória, porém com criticidades diferentes.

Os gaps com prioridade crítica estão na dimensão tangibilidade, itens 1,2 e 4 aspectos como a indisponibilidade de equipamentos modernos, e salas de aula climatizadas podem ser os fatores determinantes nestes resultados insatisfatórios. Em seguida a prioridade crítica está na dimensão da confiabilidade, itens 5 e 7 que se enquadram os problemas de comunicação clara; O gap de prioridade crítica na dimensão de segurança foi apenas o item 14, o qual demonstra baixa qualidade na segurança oferecida. Os gaps com prioridade crítica devem ser prioritariamente analisados e considerados na elaboração de planejamentos estratégicos que objetivem atender as expectativas dos usuários e promover mais qualidade.

\section{Conclusão}

Este estudo tem a importância de evidenciar como se pode melhorar a escola pública através da percepção e análise dos próprios usuários que são os estudantes e seus responsáveis, e os servidores públicos lotados. Tornar esse ambiente escolar participativo, dinâmico e inclusivo não é tarefa fácil diante de várias dificuldades e limitações enfrentados pela gestão dessas escolas.

É sabido que as atribuições do gestor escolar se diversificam no cumprimento de obrigações Pedagógica, Administrativa e Financeira. Desta forma, as questões da pesquisa pretenderam identificar o clima organizacional e como isso pode contribuir para a qualidade do serviço prestado, é essa visão integrada e sistêmica, que se compreende a articulação das práticas organizacionais, ou seja, da realidade da dimensão sociológica, política e econômica no sistema escolar. Nesta perspectiva foram analisados os professores, coordenadores e administrativos, no intuito de identificar a concepção do contexto através do clima organizacional da escola estudo de caso. E, para compreender a articulação, os limites e possibilidades da própria ação diretiva da escola, os alunos avaliam a prestação de serviço.

Essas percepções da equipe de gestão são fundamentais para estabelecer e desenvolver um ambiente escolar propicie a organização, orientação administrativa e pedagógica, e que formem alunos ou cidadãos verdadeiramente preparados para assumir seu papel em uma sociedade. Como limitações da pesquisa, não foram pesquisadas as ações do PPP e os valores adotados pela escola. 


\section{REFERÊNCIAS}

AQUINO, J. T.; MELO, F. J. C.; JERÔNIMO, T. B.; MEDEIROS, D. D. Evaluation of Quality in Public Transport Services: The Use of Quality Dimensions as an Input for Fuzzy TOPSIS. International Journal of Fuzzy Systems, v. 21, p. 176-193, 2019.

CARVALHO, B. C. M.; SILVA, M. V. R.; PAIVA, I. J. F.; MELO, F. J. C. Avaliação da qualidade em companhias aéreas com a aplicação do modelo de Kano. In: ENEGEP 2018 Encontro Nacional de Engenharia de Produção, 2018, MACEIO/AL - BRASIL, 2018. v. 28.

FERRAZ, N. A.; MELO, F. J. C.; JERÔNIMO, T. B.; ALBUQUERQUE, A. P. G.; MEDEIROS, D. D. Evaluation of quality in services: real case in the hotel fitness center. Revista brasileira de pesquisa em turismo, v. 12, p. 1-27, 2018.

JERONIMO, T. B.; AQUINO, J. T.; CORREIA, A. C.; MELO, F. J. C. O papel da avaliação de desempenho dos profissionais de Secretariado Executivo: um estudo de caso em uma instituição pública de ensino superior. In: VI Congresso Brasileiro de Engenharia de Produção (ConBRepro), 2016, PONTA GROSSAPARANÁ. ENGENHARIA DE DESENVOLVIMENTO DE PRODUTO, 2016. v. VI.

KOTLER, Philip. Administração de marketing: análise, planejamento, implementação e controle. 4. ed. São Paulo: Atlas, 1998.

NETO, P. J.S.; MELO, F. J. C.; MEDEIROS, D. D.; Avaliação da qualidade em serviços: um estudo de caso no setor fitness. In: XXV SIMPEP - Simpósio de Engenharia de produção. 2018.

MOROSINI, Marília Costa. Qualidade na educação superior: tendências do século. Estudos em avaliação educacional, v. 20, n. 43, p. 165-186, 2009.

OLIVEIRA, E. B. B.; GUIMARAES JUNIOR, D. S.; LIMA, C. W. S.; SANTANNA, C. H. M.; MELO, F. J. C. Avaliação da Qualidade dos Serviços Logísticos Prestados por Websites Utilizando o SERVQUAL. GEPROS: Gestão da Produção, Operações e Sistemas, v. 14, p. 135-145, 2019.

PADILHA, Paulo Roberto. Educar em Todos os Cantos. Por uma Educação Intertranscultural. Educación Multicultural, p. 111, 2007.

PADILHA, Paulo Roberto. Currículo intertranscultural: novos itinerários para a educação. 2004.

PARASURAMAN, A.; ZEITHAML V. A.; BERRY, L. L. A. SERVQUAL: A multiple item scale for measuring consumer perceptions of service quality. Journal of Retailing, n. 1, p.12-40, 1988.

PARASURAMAN, A.; ZEITHAML, V. A.; BERRY, L. L. A. Conceptual model of service quality and its implications for future research. Journal of Marketing, n. 4, p. 41-50, p. 1985. 